\title{
Early environmental experience and avoidance learning in the rat $^{1}$
}

ROBERT J. KIRKBY, Psychiatric Research Unit, Rozelle, N.S.W., Australia

Rats raised for 30 days postweaning in either enriched or deprived environments were tested on a simple passive-avoidance problem. Although elimination scores indicated that the environmentally deprived rats were more emotionally reactive than the enriched rats, there were no apparent differences between groups in acquiring the avoidance response.

The findings of several investigators have suggested that the ability of a rat to learn and remember could be determined by the environment in which the animal matured. For example, it has been reported that rats raised in an "enriched environment" perform better than litter mates raised in a "deprived environment" on a variety of relatively complex problem-solving (Luchins \& Forgus, 1955; Hoffman, 1959; Krech, Rosenzweig, \& Bennett, 1962) and maze-learning tasks (Hebb, 1947; Bingham \& Griffiths, 1952; Hymovitch, 1952; Forgays \& Read, 1962).

The present study was undertaken to investigate the effects of early stimulation upon a simpler learning task, one-trial passive avoidance.

\section{SUBJECTS}

The Ss were 28 Sprague-Dawley albino rats, 14 males and 14 females, selected from litters born within a 3-day period.

Environmental Training Procedure

Twenty to 23 days after birth, the rats were removed from the nursery cages and assigned to either the environmentally enriched or the environmentally deprived group. Both groups contained an equal number of male and female rats from each litter. The Ss in the environmentally enriched group were housed in a $30 \times 18 \times 16$ in. community cage placed beneath an unshaded window in the departmental workshop. Several playthings, including small plastic toys, cotton reels, colored wooden blocks, and glass jars, were placed on the floor or suspended from the ceiling of the community cage. No attempt was made to regulate the temperature or lighting in the workshop. The Ss were handled at least once daily, and at random times a radio, placed beside the cage, was played. The environmentally deprived group were placed one to a standard laboratory cage in a semi-darkened area in the colony room. These rats were not handled and were disturbed only when water bottles were changed and foodbins refilled. At the conclusion of the 30-day environmental training period, all Ss were transported to the experimental room and housed individually in standard laboratory cages. For the next 9 days, the rats underwent a standardized gentling procedure. Daily, each rat was taken from its cage, handled for $2 \mathrm{~min}$, then returned to the cage. Before the commencement of alternation testing on the 10th day, the Ss were recoded so that testing would be blind.

$$
\text { APPARATUS }
$$

A step-through apparatus similar to that utilized by Essman \& Alpern (1964) and Kimble, Kirkby, \& Stein (1966) was used. The apparatus consisted of a metal platform behind a vertical front panel. A $2 \frac{1}{2}$-in.-diam circular hole was placed in this panel $1 / 4$ in. above the level of the metal platform. A small metal perch extended from the panel at the lower edge of the hole. The small perch and the metal platform behind the hole were connected to a constant-current stimulator so that an animal stepping through the hole would close the circuit and so receive a shock of approximately $2 \mathrm{~mA}$. A $40-\mathrm{W}$ bulb was placed directly above the perch. The entire apparatus was placed on the edge of a table so that the perch extended well over the edge of the table, 54 in. above the floor.

\section{PROCEDURE}

On the first day of testing, the rats were placed, one at a time, on the small metal perch, which they invariably vacated within $30 \mathrm{sec}$ by stepping through the circular hole to the metal platform. This step-through latency (STL) was recorded. As the rat stepped through onto the metal platform, it closed the electrical circuit and received a shock. Immediately, the rat was removed from the platform and replaced in its home cage. This procedure was repeated $24 \mathrm{~h}$ later and again on the 10th day. Any increase in the STL for Days 2 and 10 was taken as an indication of learning. A rat could avoid shock completely by remaining on the perch and not stepping through the circular hole onto the platform. If the rat did not step through within $60 \mathrm{sec}$, it was removed from the perch and the STL was recorded as $60 \mathrm{sec}$. A tally was kept of the number of occasions a rat urinated or defecated between the time it was placed on the perch and the termination of the trial.

\section{RESULTS}

The STL results are shown in Table 1.
There were no significant differences between groups for Day $1(t<1)$, Day 2 $(t<1)$, or Day $10(t<1)$. As Table 2 shows, rats from both the enriched and the deprived group demonstrated a significant increase in STL between Day 1 and Days 2 and 10 . There were no significant differences in STL between Days 2 and 10 for either group. Difference scores for the STL on Day 1 minus the STL on Day 10 were calculated for each rat. The means of these scores, $29.2 \mathrm{sec}$ for the deprived group and $32.9 \mathrm{sec}$ for the enriched group, were not significantly different $(t<1)$.

A count of elimination scores showed that over the three trials the deprived group urinated on 30 occasions and defecated on 10. The enriched group urinated only 9 times and defecated not at all. Significantly more deprived rats $(N=14)$ than enriched rats $(N=7)$ urinated on at least one trial $(p<.01$, two-tailed, Fisher exact probability test). Significantly more deprived rats $(N=5)$ than enriched rats $(\mathrm{N}=0)$ defecated on at least one trial $(\mathrm{p}<.05$, two-tailed, Fisher exact probability test).

\section{DISCUSSION}

The results indicated that in the acquisition of a simple passive avoidance learning task rats raised in a deprived environment performed no differently from litter mates raised in an enriched environment. Significant differences between the groups did appear in defecation and urination scores. These differences suggested that the deprived rats were more emotionally reactive than were the enriched rats, a finding consistent with earlier reports (Denenberg \& Morton, 1962).

Three possible explanations of the present findings are: The environmental treatment did not result in any differences in learning ability; the environmental treatment did result in differences in learning ability but these differences were obscured by differences in emotionality; or, the treatment did result in differences in learning ability but these differences were not detected due to the insensitivity of the learning measure.

Considering the first possibility, differences in learning abilities have been found by other investigators utilizing stimulation techniques and "critical periods" similar to those of the present

Table 1

The Mean Step-Through Latencies (in Sec) for the Environmentally Enriched and Deprived Groups

\begin{tabular}{lcc}
\hline & Enriched & Deprived \\
\hline Day 1 & 14.3 & 11.0 \\
Day 2 & 42.7 & 43.5 \\
Day 10 & 47.1 & 40.3 \\
\hline
\end{tabular}


Table 2

Statistical Differences in Step-Through Latencies Benteen Days 1. 2, and 10

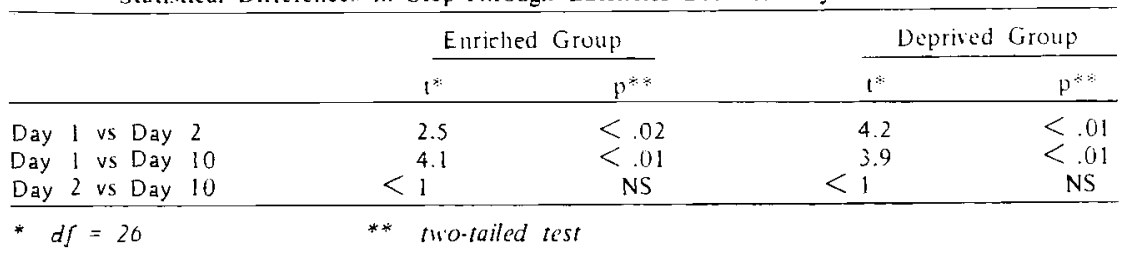

study (Hymovitch, 1952; Bingham \& Griffiths, 1952: Krech et al, 1962: Forgays \& Read, 1962). Furthermore, using the sume environmental stimulation apparatus, an identical group of Ss, and.a very similar procedure, Kirkby \& Kirkby (1968) found significant differences between enriched and deprived groups in spontaneous alternation, a phenomenon associated with learning ability (Parkes. 1965; Lester. 1967: Kirkby, 1967). Thus, it seems probable that the environmental treatment did result in differences in learning ability.

It is possible that the deprived rats. being more emotional, tended to "freeze" on the perch outside the step-through hole, so lengthening step-through latencies. However, the finding that the deprived rats vacated the perch as rapidly as the enriched rats on Day 1 indicated that this explanation was unlikely. A similar lack of differences between enriched and deprived rats in failures to leave a startbox was reported by Kirkby \& Kirkby (1969).

This leaves the third possibility, that the step-through problem was too simple a technique to detect differences in learning ability resulting from environmental treatment in rats.

In the light of the findings of Hymovitch (1952), Bingham \& Griffiths (1952), Krech et al (1962), Forgays \& Read (1962), and Kirkby \& Kirkby (1968), this explanation appears the most feasible interpretation of the present results.

\section{REFFRENCFS}

BINGHAM. W. E. \& GRII IITHS, W. J. The effects of different environments during infancy on adult behavior in the rat. Joumal of Comparative \& Physiological Psychology. 1952.45.307.312.

DF NENBERG. V. H.. \& MORTON. J. R. Effects of environmental complexity and social groupings upon modification of emotional bchavior. Journal of Comparative \& Physiological Puychology, 1962. 55, 242-246.

ISSMAN, W. B.. \& ALPERN. H. P. Single-trial conditioning methodology, and results with mice, Psychological Reports. 1964. 14. $731-740$.

IORGAYS, D. G.. \& READ. J. M. Crucial period for foremsirommentul experisnes in the rat. Journal of Comparative \& Physiological Psychology, 1962, 55, 816-818.

HFBB. D. O. The effects of early experience on problem solving at maturity. American Psychologist, 1947. 2. 306-307.

HOIFMAN. C. S. Fffect of early environmental restriction on subsequent behavior in the rat. Psychological Record. 1959.9.171-177.
HYMOVITCH. B. The effects of experimental variations on problem solving in the rat. Journal of Comparative \& Physiological Psychology. 1952.45. 313-321. Response perseveration interpretation of passive avoidance deficits in hippocampectomized rats. Journal of Comparative \& Physiolocial Psychology, 1966 , 61. 141-143.

KIRKBY, R. J. A maturation factor in spontaneous alternation. Nature. 1967, 215. 784.

KIRKBY, R. J., \& KIRKBY. J. E. Note: Early
KIMBLE. D. P., KIRKBY. R. J.. \& STEIN. D. G.
DONOVAN E. FLEMING and LELAND E. RHODES, V.A. Hospital, Phoenix, Ariz. 85012

Rats were required to make a choice based on brightness cues prior to coming in contact with either a smooth or rough tactual cue. Such a procedure was used in order to determine whether the postchoice presentation of a stimulus other than that eliciting the choice operates as a discriminative cue or whether it acquires reinforcing properties. All animals running to a rough positive cue as opposed to those running to a smooth positive cue were reliably facilitated in rate of acquisition of the task. The tactual distinctiveness of the negative door was of irrelevant cue value. The observed postchoice facilitation was interpreted to indicate that stimulation from the rough tactual cue acquired reinforcing propertics.

In a preliminary investigation. Fleming \& Rhodes (1969) utilized the successive presentation of distinctive brightness and tactual cues in a discrmination paradigm. It was necessary for a rat to make a choice on environmental experience and spontaneous alternation. Psychological Reports, 1968, 23, 1278.

KRECH, D., ROSENZWEIG, M. R., \& BENNETT. E. L. Relations between brain chemistry and problem solving among rats raised in enriched and impoverished environments. Journal of Comparative \& Physiological Psychology, 1962, 55, 801-807.

LESTER, D. Spontaneous alternation and learning in rats. Psychonomic Science, 1967, 9, 575-576.

LLCHINS, A. S., \& FORGLS, R. H. The effect of differential post-weaning environment on the rigidity of an animal's behavior. Joumal of Genetic Psychology, 1955, 86, 51-58.

PARKES, M. W. An examination of central actions characteristic of scopolamine: Comparison of central and peripheral activity in scopolamine, atropine and some synthetic basic esters. Psychopharmacologia, 1965, 7, 1-19.

\section{NOTE}

1. This investigation was supported by funds from the N.S.W. Department of Health.

\section{Facilitation of brightness discrimination with postchoice tactual stimulation}

the basis of visually mediated (black-white) cues prior to coming in contact with either a smooth or rough tactual cue. It was observed that rough tactual stimuli, when associated with the positive brightness cue, reliably facilitated the acquisition of the brightness discrimination with both intact and neodecorticated Ss. On the other hand, the association of distinctive tactual stimuli with the negative brightness cue had questionable effects on task acquisition. Under some conditions, the rough negative cue appeared either to hinder or to facilitate the acquisition of the brightness discrimination. For the most part, however, the tactual component of the negative brightness cue appeared to be irrelevant to the task. The data favored the interpretation that, rather than operating as a discriminative cue, the rough tactual cue apparently acquired reinforcing properties. To explore the feasibility of this interpretation, the investigation was replicated and extended. Special attention was directed to the role of the tactual component of the negative brightness cue. SUBJECTS

Forty-eight adult male albino rats of the 